\title{
The Effects of Motivational Interviewing on Asthma Control Among Adolescents with Asthma
}

\author{
Fatemeh Taheri (iD ${ }^{1}$, Ahmad Nasiri (iD) ${ }^{2,{ }^{*}}$ and Saber Mohammadzade Rezaii (iD ${ }^{3}$ \\ Master of Psychiatric Nursing, Birjand Faculty of Nursing and Midwifery, Birjand, Iran \\ ${ }^{2}$ Faculty of Nursing and Midwifery, Birjand University of Medical Sciences, Birjand, Iran \\ ${ }^{3}$ Medical Faculty, Birjand University of Medical Sciences, Birjand, Iran \\ "Corresponding author: Associate Professor, Infectious Disease Research Center, Birjand University of Medical Sciences, Birjand, IR Iran. Tel: +98-5632381406, Email: \\ nasiri2006@bums.ac.ir
}

Received 2018 August 22; Revised 2018 October 20; Accepted 2018 November 12.

\begin{abstract}
Background: Asthma is one of the most common chronic conditions of the respiratory system. Besides its physical health problems, asthma negatively affects quality of life. Psychological interventions, such as motivational interviewing, have significant roles in improving patient outcomes. As a client-centered psychological intervention, motivational interviewing may enhance motivation for behavior modification. The present study aimed to evaluate the effects of motivational interviewing on asthma control among adolescents with asthma.

Methods: This randomized controlled clinical trial was conducted in 2017 on 64 adolescents with asthma who referred to the clinic and the pediatric ward of Valiasr (PBUH) hospital in Birjand. They were conveniently selected and randomly allocated to either a control or an intervention group. Participants in the intervention group were provided with motivational interviewing in five 60-80-minute sessions. All participants filled out the Asthma Control Questionnaire before, one week, and three months after the intervention. Repeated Measures ANOVA test as well as independent-sample $t$-test and Chi-square test were used to analyze the data at a significance level of 0.05 .

Results: Before the intervention, there was no significant difference between the groups' demographic characteristics and mean score of asthma control $(\mathrm{P}>0.05)$.However, one week and three months after the intervention, the mean score of asthma control in the intervention group were significantly less than the control group $(\mathrm{P}<0.001)$, indicating better asthma control in the intervention group.

Conclusions: Motivational interviewing significantly improves asthma control among adolescents with asthma. Thus, it can be used to improve asthma control and patient outcomes among these adolescents.
\end{abstract}

Keywords: Asthma, Adolescents, Motivational Interviewing

\section{Background}

Asthma is globally the most prevalent chronic condition of childhood and adolescence $(1,2)$ It has an increasing prevalence (3) so that the number of afflicted patients worldwide is estimated to reach 400 million by 2020 (4). Asthma is a chronic inflammatory disease of the airways that results in the oversensitivity of the airways, mucosal edema, and excessive mucus production. It causes recurrent symptoms such as a cough, lung tightness, wheezing, and dyspnea, all of which are very discomforting for patients and can negatively affect their daily functioning and quality of life (5).

Disease control is the main goal of long-term management of asthma. The term "asthma control" means the extent to which an afflicted patient can reduce or even eradi- cate the clinical manifestations of the disease. Asthma control has two main components. The first is the clinical control that includes the management of current symptoms and the improvement of patient's ability to do activities of daily living in order to achieve the highest possible level of quality of life. The other component of asthma control is the control of complications and the prevention of disease aggravation (6). However, most patients may be unable to effectively control their asthma even with quality medical treatments (7) and hence, psychological interventions may be needed to help improve asthma control.

Motivational interviewing (MI) is among the newest methods for behavior modification (8). It was developed by Miller and Rollnick (9) based on Rogers' client-centered therapy approach to psychotherapy (10). The MI is an

Copyright ( ) 2019, Modern Care Journal. This is an open-access article distributed under the terms of the Creative Commons Attribution-NonCommercial 4.0 International License (http://creativecommons.org/licenses/by-nc/4.0/) which permits copy and redistribute the material just in noncommercial usages, provided the original work is properly cited. 
attempt for promoting individual's self-efficacy and selfcontrol for behavior modification. The MI works based on motivation enhancement through interactive and sympathetic listening. It greatly focuses on the difference between personal goals and current behaviors (11). The MI enables clients to explicitly articulate their ambivalences, identify their conflicting motivations and satisfactorily solve them, and modify their behaviors under the direct guidance and supervision of an interviewer (9). It is a flexible method and can be used in either personal or group interviews. The latter provides the hope for successful problem solving, facilitates information acquisition from reliable sources, reduces social isolation, promotes altruism, and facilitates cognitive behavior modifications (12).

A study on 25 adults with asthma reported that MI significantly promoted their medication adherence (13). Another study also reported its effectiveness in significantly promoting self-efficacy among 37 adolescents with asthma (14). Other studies also reported the positive effects of MI on the different aspects of behavior among patients with chronic conditions such as renal failure and hemodialysis (15), psoriasis (16), and hypertension (17). However, the above-mentioned study on 37 adolescents with asthma reported the insignificant effects of MI on medication adherence (14). Moreover, most previous studies on asthma control used educational interventions rather than MI. For instance, an earlier study reported the positive effects of asthma education on asthma control (7).

\section{Objectives}

Due to the lack of studies into the effects of MI on asthma control, the present study was carried out to evaluate the effects of MI on asthma control among adolescents with asthma.

\section{Methods}

This randomized controlled clinical trial was conducted in 2017 on 64 adolescents with asthma who referred to the clinic and the Pediatric Ward of Valiasr (PBUH) Hospital, Birjand, Iran. The sample size was calculated based on the results of a former study (8) and with a $\mu_{1}$ of 19.7, a $\mu_{2}$ of 14.2, an $S_{1}$ of 3.6, an $S_{2}$ of 5.6, a power of 0.90, and a confidence level of $95 \%$. The sample size calculation (Equation 1) showed that 29 participants were needed for each group. The sample size was increased to 32 considering an attrition rate of $10 \%$.

Equation 1. Sample size calculation.

$n=\frac{\left(z_{1-\frac{\alpha}{2}}+z_{1-\beta}\right)^{2}\left(s_{1}{ }^{2}+s_{2}{ }^{2}\right)}{\left(\mu_{1}-\mu_{2}\right)^{2}}$
A convenience sampling was used to recruit eligible adolescents to the study. The eligibility criteria were an age of $10-15$, asthma diagnosis by a specialist at least one year before the study, willingness for participation in the study, parental consent for participation, basic literacy skills, use of at least one inhaled asthma medication, and no mental disorders. The exclusion criteria included more than one absence from MI sessions and withdrawal from the study due to events such as accident or death. At the first faceto-face contact with participants and their parents, we informed them about the study and obtained parents' consent for participation. For random allocation of participants to either of the study groups, each of them was provided with a card labeled A (i.e. control group) and a card labeled B (i.e. intervention group) and was asked to randomly select one card. The label on the card determined the group allocation of the intended participant.

Two questionnaires were used for data collection. The first was a demographic questionnaire with items on age, gender, education level, family income, father's and mother's employment status, and place of residence. The second was the Asthma Control Questionnaire with seven items on nighttime awakening, symptom severity upon awakening, activity limitation, shortness of breath, wheezing, number of sprayed puffs, and forced expiratory volume in the past week. Item scoring was done using a sevenpoint scale from zero ("no symptom or limitation") to six ("severe symptom or impairment"). The total score of the questionnaire ranged from zero (good asthma control) to 42 (poor asthma control). A former study in Iran reported a Cronbach's alpha of 0.80 for the Persian version of the questionnaire (18).

Before the intervention, all participants filled out the study questionnaires. Then, participants in the intervention group were divided into two eleven-person and one ten-person subgroups and then, each subgroup was provided with MI in five 60 - 80-minute weekly sessions. The MI sessions were held based on the approach recommended by Miller and Rollnick (19). Each participant was required to attend each MI session with either of his/her parents. In the first session, the participants and the interviewer (i.e. the first author) got familiar with each other and group norms and regulations were explained. Then, group members were evaluated respecting their latitude, independence, commitment, confidence, and factors affecting their behaviors. The second session was on the assessment of participants' feelings about their asthma-related behaviors. Accordingly, a list of positive and negative feelings was provided to each participant and he/she was asked to identify his/her feelings and explain them for other group members. In the third session, brainstorming was used to assess the short- and long-term advantages and 
disadvantages of behaviors. The positive and negative aspects of each behavior were written in a table and behavior modification strategies were described and exercised. In the fourth session, participants' values were identified and prioritized, value-behavior gaps were identified, and strategies for filling the gaps were exercised. Finally, in the fifth session, tempting situations were identified and the content of previous sessions was reviewed. On the other hand, participants in the control group received no specific intervention. The posttest was performed for all participants one week and three months after the final MI session.

Study data were analyzed via the SPSS software (V.19.0). First, the groups were compared concerning participants' demographic characteristics through the chi-square test. Then, the Kolmogorov-Smirnov test was performed to test the normality of asthma control scores. Its results revealed the normal distribution of the scores. Subsequently, the repeated-measures analysis of variance, the independentsample $t$, and Bonferroni's post hoc tests were used to analyze the data at a significance level of less than 0.05 .

\subsection{Ethical Considerations}

The ethical approval and necessary permissions for the study were obtained from Birjand University of Medical Sciences, Birjand, Iran (approval code: IR.BUMS.REC.1395.179). Moreover, arrangements for the study were made with the authorities of the study setting. Participants and their parents were provided with information about the study and the confidential management of the study data. Then, parent informed consent was secured.

\section{Results}

The mean of participants' age was $11.66 \pm 1.62$. The mean age in the control and intervention groups was 11.96 \pm 1.84 and $11.56 \pm 1.41$, respectively. Most participants in both groups were males (62.5\% and $59.4 \%$, respectively) and all of them were students. Study groups did not significantly differ from each other concerning participants' age, gender, education level, father's and mother's employment status, family income, and place of residence ( $\mathrm{P}>$ 0.05; Table 1).

The between-group difference respecting the pretest mean score of asthma control was not statistically significant $(P=0.62)$. However, one week after the intervention, the mean score of asthma control in the intervention group was significantly less than that of the control group $(\mathrm{P}=0.003)$. Similarly, at the three-month follow-up assessment, the mean score of asthma control in the interven-

\begin{tabular}{|c|c|c|c|}
\hline Characteristics & $\begin{array}{l}\text { Intervention }(\mathbf{n}= \\
32)\end{array}$ & Control $(n=32)$ & PValue $^{\text {b }}$ \\
\hline Gender & & & 0.79 \\
\hline Female & $13(40.6)$ & $12(37.5)$ & \\
\hline Male & $19(59.4)$ & $20(62.5)$ & \\
\hline Education level & & & 0.22 \\
\hline Primary & $23(71.9)$ & $21(65.6)$ & \\
\hline $\begin{array}{l}\text { Guidance } \\
\text { school }\end{array}$ & $2(6.2)$ & $0(0.0)$ & \\
\hline High school & $7(21.9)$ & $11(34.4)$ & \\
\hline $\begin{array}{l}\text { Father's } \\
\text { employment }\end{array}$ & & & 0.82 \\
\hline $\begin{array}{l}\text { Self- } \\
\text { employed }\end{array}$ & $23(71.9)$ & $21(65.6)$ & \\
\hline Employee & $6(18.8)$ & $8(25.0)$ & \\
\hline Teacher & $3(9.3)$ & $3(9.4)$ & \\
\hline $\begin{array}{l}\text { Mother's } \\
\text { employment }\end{array}$ & & & 0.79 \\
\hline Employed & $21(65.6)$ & $22(68.7)$ & \\
\hline Housewife & $11(34.4)$ & $10(31.3)$ & \\
\hline Place of residence & & & 0.08 \\
\hline Urban areas & $31(96.9)$ & $27(84.4)$ & \\
\hline Rural areas & $1(3.1)$ & $5(15.6)$ & \\
\hline Family income (\$) & & & 0.75 \\
\hline Less than 85 & $9(28.1)$ & $11(34.4)$ & \\
\hline $86-210$ & $21(65.6)$ & $20(62.5)$ & \\
\hline $\begin{array}{l}\text { More than } \\
210\end{array}$ & $2(6.3)$ & $1(3.1)$ & \\
\hline
\end{tabular}

${ }^{a}$ Values are expressed as No. (\%)

${ }^{\mathrm{b}}$ The results of the chi-square test.

tion group was still significantly less than that of the control group $(\mathrm{P}<0.001$; Table 2$)$.

The variations of the mean score of asthma control in the control group were not statistically significant across the three measurement time points $(\mathrm{P}>0.05)$. However, there was at least one statistically significant difference in the intervention group respecting the variations of the asthma control mean score across the three measurement time points $(\mathrm{P}<0.05)$. The results of Bonferroni's post hoc test illustrated that the differences between pretest mean score and posttest and follow-up mean scores of asthma control in the intervention group were statistically significant $(\mathrm{P}<0.001)$, while there was no statistically significant difference between the posttest and the follow-up mean scores $(\mathrm{P}=0.19$; Table 3$)$.

Finally, the between-group differences respecting the 


\begin{tabular}{|c|c|c|c|c|c|c|}
\hline \multirow{2}{*}{ Group } & \multirow{2}{*}{ Pretest } & \multirow{2}{*}{ Posttest } & \multirow{2}{*}{ Follow-up } & \multicolumn{3}{|c|}{ PValue $^{\text {b }}$} \\
\hline & & & & Pretest-Posttest & Pretest-Follow-up & Posttest-Follow-up \\
\hline Intervention & $11.11 \pm 6.35$ & $6.44 \pm 3.85$ & $5.88 \pm 3.32$ & $<0.001$ & $<0.001$ & 0.19 \\
\hline Control & $10.36 \pm 6.47$ & $10.05 \pm 6.21$ & $10.27 \pm 6.19$ & 0.42 & 0.94 & 0.94 \\
\hline Pvalue $^{c}$ & 0.62 & 0.003 & $<0.001$ & - & - & - \\
\hline
\end{tabular}

${ }^{\text {a }}$ Values are expressed as mean $\pm \mathrm{SD}$.

${ }^{\mathrm{b}}$ The results of the repeated-measures analysis of variance.

${ }^{\mathrm{c}}$ The results of the independent-sample $t$ test.

Table 3. Between-Group Comparisons Concerning the Mean Differences of Asthma Control Mean Scores

\begin{tabular}{lccc}
\hline Group & Pretest-Posttest & $\begin{array}{c}\text { Pretest-Follow- } \\
\text { up }\end{array}$ & $\begin{array}{c}\text { Posttest-Follow- } \\
\text { up }\end{array}$ \\
\hline Intervention & $-4.66 \pm 3.82$ & $-5.22 \pm 4.02$ & $-0.55 \pm 1.74$ \\
Control & $-0.30 \pm 1.21$ & $-0.08 \pm 1.27$ & $0.22 \pm 1.41$ \\
\hline Pvalue $^{\mathrm{b}}$ & $<0.001$ & $<0.001$ & 0.23 \\
\hline
\end{tabular}

${ }^{\text {a }}$ Values are expressed as mean $\pm \mathrm{SD}$.

${ }^{\mathrm{b}}$ The results of the independent-sample $t$ test

mean difference between the pretest and the posttest and follow-up mean scores of asthma control were statistically significant $(\mathrm{P}<0.001)$, while the between-group difference respecting the mean difference between the posttest and follow-up mean scores of asthma control was not statistically significant $(\mathrm{P}=0.23)$.

\section{Discussion}

This study aimed to evaluate the effects of MI on asthma control among adolescents with asthma. The findings indicated that MI significantly improved symptoms and disease control. Although we found no similar studies for comparison, some studies were found into the effects of education on asthma control or the effects of MI on other patient outcomes. For instance, a study reported asthma education meeting to be effective in improving asthma control (7). Another study found that educations about using peak flow meter and message-based follow-up significantly improved self-management among patients with asthma (20). However, a short-term educational intervention was found to have no significant effects on asthma control and treatment adherence (3). Most educational interventions for asthma mostly focused on the enhancement of patients' knowledge about asthma and its treatments (21). However, the present study revealed that helping patients focus more on asthma, its symptoms, and their causes could significantly improve asthma symptoms and asthma control.
Respecting the effects of MI on other patient outcomes, a study in the United States on 37 adolescents with asthma and their caregivers reported that MI significantly enhanced adolescents' self-efficacy and motivation for receiving treatment, promoted their caregivers' treatment adherence, and had no significant effects on adolescents' treatment adherence (14). Another study indicated the effectiveness of MI in treatment adherence of 25 adults with asthma (13). Similarly, a study on 54 adults with asthma reported the positive effects of MI on treatment adherence even one year after the intervention (22).

The current asthma management guidelines show that the aim of treatment is to help patients effectively to control their disease (23). The MI can help the therapist to achieve this aim because it is based on sympathetic interaction, avoidance from struggling with the client, coping with his/her resistance, supporting his/her self-efficacy, and encouraging behavior modification (12). The appropriate use of MI can effectively improve asthma control. Of course, further studies with longer follow-up assessment periods are needed to provide firm evidence concerning the effectiveness of MI in improving asthma control.

Among the limitations for the present study was the lack of asthma-specific clinics in Birjand, Iran, which faced us with difficulties in accessing eligible participants for this study.

\subsection{Conclusions}

This study suggests the effectiveness of MI in improving disease control among adolescents with asthma. Improving adolescents' motivation for the modification of behaviors that aggravate asthma symptoms may have considerable effects on asthma control and quality of life. Educational managers are recommended to adopt strategies to teach MI and its applications to nurses who work with adolescents who suffer from asthma.

\section{Acknowledgments}

This study was approved by the Birjand University of Medical Sciences, Birjand, Iran. We would like to thank the 
Research Administration of the University that helped and supported us throughout this study.

\section{Footnotes}

Conflict of Interests: The authors declare that they had no conflict of interests to declare.

Funding/Support: None declared.

Ethical Considerations: IR.BUMS.REC.1395.179.

\section{References}

1. Wilson D, Hockenberry MJ. Wong's clinical manual of pediatric nursing. 8th ed. ST Louis: Mosby Elsevier; 2009. p. 783-94.

2. Orrell-Valente JK, Jarlsberg LG, Hill LG, Cabana MD. At what age do children start taking daily asthma medicines on their own? Pediatrics. 2008;122(6):e1186-92. doi: 10.1542/peds.2008-0292. [PubMed: 19047221].

3. Dalcin Pde T, Grutcki DM, Laporte PP, Lima PB, Viana VP, Konzen GL, et al. Impact of a short-term educational intervention on adherence to asthma treatment and on asthma control. J Bras Pneumol. 2011;37(1):19-27. [PubMed: 21390428].

4. Ownby DR. Pet dander and difficult-to-control asthma: The burden of illness. Allergy Asthma Proc. 2010;31(5):381-4. doi: 10.2500/aap.2010.31.3389. [PubMed: 20929604].

5. Paul P, Williams B. Brunner \& Suddarth's textbook of Canadian medicalsurgical nursing. 12th ed. Philadelphia: Lippincott Williams \& Wilkins; 2009.

6. Werner CU, Linde K, Schaffner J, Storr C, Schneider A. Weekly selfmeasurement of FEV1 and PEF and its impact on ACQ (asthma control questionnaire)-scores: 12-week observational study with 76 patients. NPJ Prim Care Respir Med. 2017;27(1):64. doi: 10.1038/s41533-017-0064-4. [PubMed: 29222436]. [PubMed Central: PMC5722863].

7. Kavut $A B$, Kalpakloglu AF. Impact of asthma education meeting on asthma control level assessed by asthma control test. World Allergy Organ J. 2010;3(1):6-8. doi: 10.1097/WOX.0b013e3181c82002. [PubMed: 23282380]. [PubMed Central: PMC3651062].

8. Knight KM, McGowan L, Dickens C, Bundy C. A systematic review of motivational interviewing in physical health care settings. BrJHealth Psychol. 2006;11(Pt 2):319-32. doi: 10.1348/135910705X52516. [PubMed: $16643702]$.

9. Miller WR, Rollnick S. Motivational interviewing: Helping people change. 3rd ed. New York: Guilford Press; 2012.

10. Rogers $C R$. The necessary and sufficient conditions of therapeutic personality change. J Consult Psychol. 1957;21(2):95-103. doi: 10.1023/A:1011365519345. [PubMed: 13416422].

11. DiLillo V, Siegfried NJ, Smith West D. Incorporating motivational interviewing into behavioral obesity treatment. Cognit Behav Pract. 2003;10(2):120-30. doi: 10.1016/s1077-7229(03)80020-2.
12. Araban M, Tavvafian SS, Motesaddi ZS, Heidarnia AR, Gohari MR, Laloie $A$, et al. [Effectiveness of a motivational interviewing session to enhance self-efficacy of npregnant women in response to air pollution preventive behaviors: A randomized trial]. Payesh. 2014;13(1):83-90. Persian.

13. Schmaling KB, Blume AW, Afari N. A randomized controlled pilot study of motivational interviewing to change attitudes about adherence to medications for asthma. J Clin Psychol Med Setting. 2001;8(3):167-72. doi: 10.1023/a:1011365519345.

14. Riekert KA, Borrelli B, Bilderback A, Rand CS. The development of a motivational interviewing intervention to promote medication adherence among inner-city, African-American adolescents with asthma. Patient Educ Couns. 2011;82(1):117-22. doi: 10.1016/j.pec.2010.03.005. [PubMed: 20371158]. [PubMed Central: PMC2937081].

15. Makvand Hosseini S, Ersi K, Moemeni A. [Effectiveness of motivational interviewing on treatment adherence in dialysis patients in Hajar Hospital of Shahrekord, 2013]. J Shahrekord Univ Med Sci. 2015;17(4). Persian.

16. Larsen MH, Wahl AK, Krogstad AL, Aas E. Cost-utility analysis of supported self-management with motiva-tional interviewing for patients with psoriasis. Acta Derm Venereol. 2016;96(5):664-8. doi: 10.2340/00015555-2331. [PubMed: 26714522].

17. Mirkarimi K, Honarvar M, Ariaie M, Bordi R, Kamran A. [Effect of motivational interviewing on adherence to treatment in patients with hypertension]. Quart Horizon Med Sci. 2015;21(3):213-20. Persian. doi: 10.18869/acadpub.hms.21.3.213.

18. Aghdam AM, Hasankhani H, Gharemohammadlu R, Esmaeily M. [Relation of patients self-efficacy with control of asthma symptoms]. $J$ Gorgan Univ Med Sci. 2013;15(2). Persian.

19. Navidiyan A, Pour Sharifi H. Practical guide to motivational interviewing. Zahedan: Sokhan Gostar Pub; 2012. p. 98-166. Persian.

20. Razi SP, Piroozmand N, Zolfaghari M, Kazemnejad A, Firoozbakhsh S. [Education of how-to-use peak flow meter and following up via SMS on asthma self-management].J Facult Nurs Midwifery. 2012;18(4):19-27. Persian.

21. Guevara JP, Wolf FM, Grum CM, Clark NM. Effects of educational interventions for self management of asthma in children and adolescents: Systematic review and meta-analysis. BMJ. 2003;326(7402):1308-9. doi: 10.1136/bmj.326.7402.1308. [PubMed: 12805167]. [PubMed Central: PMC161636]

22. Lavoie KL, Moullec G, Lemiere C, Blais L, Labrecque M, Beauchesne $M F$, et al. Efficacy of brief motivational interviewing to improve adherence to inhaled corticosteroids among adult asthmatics: Results from a randomized controlled pilot feasibility trial. Patient Prefer Adherence. 2014;8:1555-69. doi: 10.2147|PPA.S66966. [PubMed: 25422587]. [PubMed Central: PMC4231985].

23. Gazzotti MR, Nascimento OA, Montealegre F, Fish J, Jardim JR. Level of asthma control and its impact on activities of daily living in asthma patients in Brazil. J Bras Pneumol. 2013;39(5):532-8. doi: 10.1590/S1806-37132013000500002. [PubMed: 24310625]. [PubMed Central: PMC4075876]. 